\title{
Intestinal parasitic infections in a population of BaAka Pygmies inhabiting the Congo Basin in the Central African Republic
}

\author{
Krzysztof Korzeniewski ${ }^{1,2, A, D-F \oplus}{ }^{\oplus}$ Alina Augustynowicz ${ }^{1, B-C}{ }^{\oplus}$, Emilia Bylicka-Szczepanowska ${ }^{3, B}{ }^{\oplus}$, \\ Dagmara Pokorna-Kałwak ${ }^{4, C}(\odot)$ \\ ${ }^{1}$ Military Institute of Medicine, Warsaw, Poland \\ ${ }^{2}$ Medical University, Gdańsk, Poland \\ ${ }^{3}$ Provincial Hospital for Infectious Diseases, Warsaw, Poland \\ ${ }^{4}$ Medical University, Wrocław, Poland \\ A - Research concept and design, B - Collection and/or assembly of data, C - Data analysis and interpretation, \\ $D$ - Writing the article, E - Critical revision of the article, F - Final approval of article
}

Korzeniewski K, Augustynowicz A, Bylicka-Szczepanowska E, Pokorna-Kałwak D. Intestinal parasitic infections in a population of BaAka
Pygmies inhabiting the Congo Basin in the Central African Republic. Ann Agric Environ Med. 2021; 28(1): 127-130. doi: 10.26444/aaem/131648

\section{Abstract}

Introduction. Pygmy tribes inhabit tropical environment of Central Africa. After expulsion from their original habitat by the Bantu people, they settled in a local forest ecosystem where they live with very low sanitary standards. Their actual morbidity remains unknown.

Objective. The aim of the study was to analyze the prevalence of intestinal parasitic infections in BaAka Pygmies inhabiting the Congo Basin in the Central African Republic.

Materials and method. The study was conducted in 2015, and involved a group of 950 Pygmies living inthe Sangha-Mbaere and Lobaye prefectures. Single stool samples were collected from study participants, fixed in 10\% formalin, transported from Africa to Europe, and analyzed by light microscopy using 5 different diagnostic methods (direct smear, decantation with distilled water, Fülleborne's flotation, Kato-Miura thick smear, DiaSyS/PARASYS system sedimentation) at the Military Institute of Medicine in Warsaw, Poland.

Results. Microscopic examination revealed infections with 14 different species of intestinal nematodes, cestodes, trematodes and protozoa. According to the study findings, $90.5 \%$ of BaAka Pygmies were found to be infected with intestinal parasites, and $70.8 \%$ had mixed infections. Most of the pathogenic intestinal parasites were nematodes (85.0\%), with Asrcaris lumbricoides (29.8\%), hookworm (29.4\%) and Trichuris trichiura (10.7\%) being predominant.

Conclusions. Poor sanitation, limited the high prevalence of intestinal parasitic infections in the community of Pygmies. The negative test results may prove the effectiveness of periodic deworming campaigns chich, implemented by nongovernmental organizations, are voluntary with respect to the informed consent principle.

\section{Kew words}

risk factors, intestinal parasites, Central African Republic, Pygmies

\section{INTRODUCTION}

Gastrointestinal parasitic infections remain one of the biggest challenges to modern medicine. Depending on the region, from $5-90 \%$ of the global population may be affected. The World Health Organization (WHO) estimates that approximately $25 \%$ of the world population is infected with at least one intestinal parasite species [1,2]. Intestinal parasitic infections are commonly named neglected diseases and are still disregarded by medical services in many countries, which results in the spread of infections beyond endemic regions [3]. Poor sanitary conditions, low level of medical care, and the presence of reservoirs of the intestinal parasites in endemic regions, all contribute to the spread of parasitic diseases, both in developing as well as in developed countries $[4,5,6]$.

Nematodes are one of the most common pathogens inhabiting the human digestive tract. It is estimated, that approximately 1 billion people worldwide are infected with

Address for correspondence: Krzysztof Korzeniewski, Military Institute of Medicine, Szaserów St. 128, 04-141, Warsaw, Poland

E-mail: kkorzeniewski@wim.mil.pl

Received: 28.10.2020; accepted: 14.12.2020; first published: 28.12.2020
Ascaris lumbricoides. Infections of hookworm (Ancylostoma duodenale, Necator americanus) are also very common (500-700 million infected) globally [3]. In most cases, the source of infection with A. lumbricoides is food, water and soil contaminated with the parasite's eggs. Ancylostomidae infection, on the other hand, occurs by direct penetration of invasive larvae through the skin of the host; this type of infection is easily transmitted in areas where people walk barefoot; transmission usually occurs through contact with wet soil contaminated with parasite larvae. Another intestinal helminth which has a worldwide distribution is Trichuris trichiura (500 million infected); an infection by this species is caused by consumption of water or food contaminated with the parasite's eggs [7].

The Central African Republic is an example of a developing country where sanitary conditions fail to reach universal standards, and where access to uncontaminated water sources and safe and nutritious food is seriously limited [8]. Exceptionally high birth rates and poor living standards on the African continent, especially in sub-Saharan Africa, contribute to the rapid spread of parasitic diseases, especially those transmitted via the faecal-oral route. 
Pygmy tribes (e.g. Mbuti, Twa, BaAka) inhabiting tropical forests in Central Africa, are an example of a population living under very poor sanitary conditions. Additionally, their socio-economic status is extremely low. Pygmies lead a semi-nomadic lifestyle, and because they are regularly expelled from their habitats by sedentary Bantu people, they are forced to move from one place to another across the rainforests in the Democratic Republic of Congo, Gabon, Cameroon and the Central African Republic. The current Pygmy population in the Congo Basin has been estimated to be over 100,000. Pygmies lead their lives in harmony with nature, are a population of hunter-gatherers and do not cultivate land or breed animals. Therefore, their diet is very poor in nutrients. Additionally, they have limited access to uncontaminated drinking water, and have very poor personal hygiene habits. Their nomadic lifestyle is a relevant risk factor for gastrointestinal parasitic diseases [9].

In 2008, the Pygmy people were listed on the UNESCO's Representative List of the Intangible Cultural Heritage of Humanity, in recognition of their unique lifestyle and tribal traditions [9]. Because Pygmies live in small, closed groups in hardly accessible regions of the Africa rainforests, there has been very little medical or epidemiological research into the population. Therefore, little is known about the health status of the Pygmy people and the rates of infectious diseases within the community.

\section{OBJECTIVES}

The aim of this study was to assess the prevalence of intestinal parasitic infections in the BaAka Pygmies population inhabiting the Congo Basin rainforests in the south-western parts of the Central African Republic.

\section{MATERIALS AND METHOD}

Study population. The study was conducted in 2015, and involved a group of $950 \mathrm{BaAka}$ Pygmies inhabiting the region of Monasao (Sangha-Mbaere prefecture) and Bagandou (Lobaye prefecture) in the south-western parts of the Central African Republic. Each patient could participate in the project, regardless of age, gender and health condition. Information for the patient and an informed consent form were translated to the Sango language which is widely used within the local population. The mean age of the study subjects was 16.8 ; the majority were $\leq 18$ years old (63.2\%). Females accounted for $62.2 \%$ of the study group, while males represented $37.8 \%$ of the sample.

Sample collection and laboratory procedures. The biological material for coprological diagnostics consisted of single stool samples provided by the patients. Stool samples were collected into special containers provided by local healthcare centres located in the vicinity of the Catholic missions in Monasao and Bagandou, in the south-west Central African Republic. The samples were delivered to the healthcare facility on a collection day. Next, the material was fixed in $10 \%$ formalin and after $1-2$ weeks it was transported to the Department of Epidemiology and Tropical Medicine of the Military Institute of Medicine in Warsaw, Poland, where laboratory examination by light microscopy was performed using 5 different diagnostic methods (direct smear in Lugol's solution, decantation in distilled water, Fülleborne's flotation, Kato-Miura thick smear, DiaSys/PARASYS system sedimentation) $[10,11]$. Thus, a total of 4,750 parasitological tests were performed. Microscopic examination allowed determination of the number of parasitic infections in the study group.

Statistics. All statistical calculations were performed using the suite StatSoft Inc. (2014) STATISTICA version 12.0 (www.statsoft.com, and an Excel spreadsheet. The quantitative variables were characterized by the arithmetic mean and minimum/maximum value (range). The variables of the qualitative type were presented in terms of counts and percentages. In all calculations, the level of statistical significance was set at $\mathrm{p}=0.05$.

\section{RESULTS}

Microscopic examination of the samples obtained from the 950 BaAka Pygmies revealed that 860 of them $(90.5 \%$ of the study group) were infected with intestinal parasites. The total number of infections was 2,150, with nematodes responsible for the majority of infections (85.0\%). Coprological examination of the stool specimens revealed 14 different species of pathogenic intestinal parasites, with Ascaris lumbricoides (29.8\%), hookworm (29.4\%) and Trichuris trichiura (10.7\%) being predominant. A significant number of infections was caused by protozoa (14.2\%), mostly Giardia intestinalis (8.1\%). The lowest ratio of detected pathogens was represented by trematodes and cestodes infections (Tab. 1, Fig. 1).

Table 1. Distribution of pathogenic intestinal parasites detected in the group of BaAka Pygmies $(n=950)$, south-west Central African Republic in 2015

\begin{tabular}{|c|c|c|c|}
\hline Intestinal parasites & $\begin{array}{c}\text { Number } \\
\text { (percentage) of } \\
\text { infections }\end{array}$ & $\begin{array}{c}\text { Percentage } \\
\text { of infected } \\
\text { patients }(n=860)\end{array}$ & $\begin{array}{l}\text { Percentage of } \\
\text { tested patients } \\
\quad(n=950)\end{array}$ \\
\hline Nematodes & $1827(85.0)$ & & \\
\hline Ascaris lumbricoides & $640(29.8)$ & 74.4 & 67.3 \\
\hline Hookworm & $633(29.4)$ & 43.6 & 66.6 \\
\hline Trichuris trichiura & $229(10.7)$ & 26.6 & 24.1 \\
\hline Trichostrongylus sp. & $169(7.9)$ & 19.6 & 17.8 \\
\hline Strongyloides stercoralis & $114(5.3)$ & 13.3 & 12.0 \\
\hline Capillaria sp. & $35(1.6)$ & 4.1 & 3.7 \\
\hline Enterobius vermicularis & $7(0.3)$ & 0.8 & 0.7 \\
\hline Cestodes & $5(0.2)$ & & \\
\hline Hymenolepis nana & $3(0.1)$ & 0.3 & 0.3 \\
\hline Taenia sp. & $2(0.1)$ & 0.2 & 0.2 \\
\hline Trematodes & $12(0.6)$ & & \\
\hline Dicrocoelium dendriticum & $7(0.3)$ & 0.8 & 0.7 \\
\hline Fasciola hepatica & $3(0.1)$ & 0.3 & 0.3 \\
\hline Schistosoma mansoni & $2(0.1)$ & 0.2 & 0.2 \\
\hline Protozoa & $306(14.2)$ & & \\
\hline Giardia intestinalis & $175(8.1)$ & 20.3 & 18.4 \\
\hline $\begin{array}{l}\text { Entamoeba histolytica sensu } \\
\text { lato }\end{array}$ & $131(6.1)$ & 15.2 & 13.8 \\
\hline Total & $2150(100.0)$ & & \\
\hline
\end{tabular}




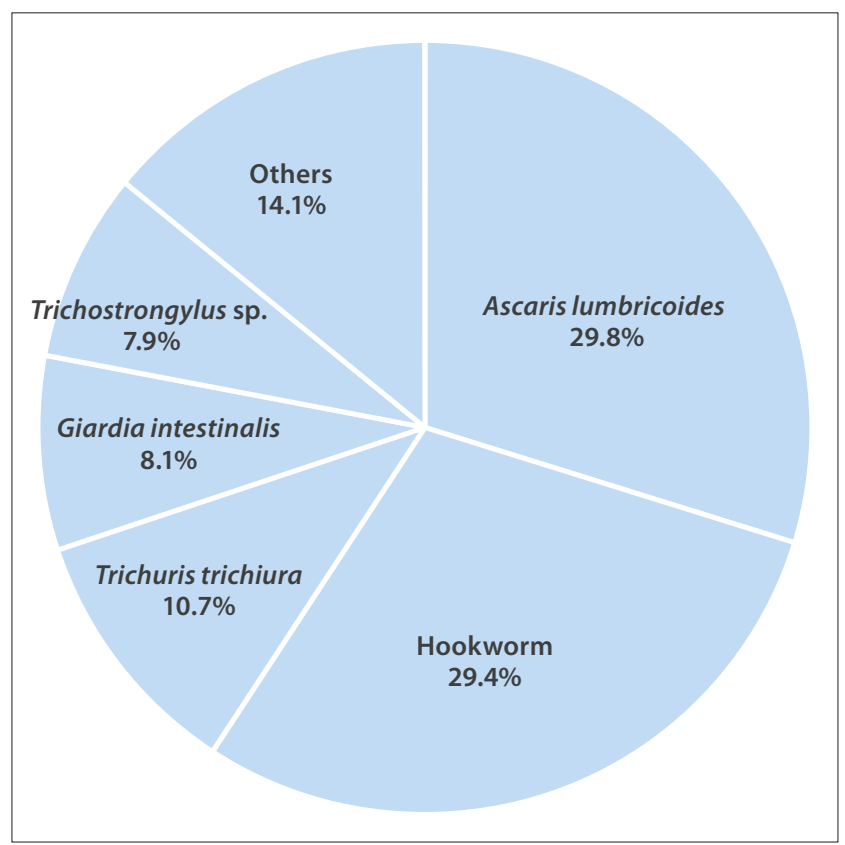

Figure 1. The most common pathogenic intestinal parasites detected in the group of BaAka Pygmies ( $n=950)$, south-west Central African Republic in 2015

Most infections found in the group of BaAka Pygmies ( $\mathrm{n}=673,70.8 \%$ ) were mixed invasions (polyparasitism); the co-invasion of Ascaris lumbricoides with hookworm was predominant (Tab. 2).

Table 2. The most common co-invasions of intestinal parasites detected in the group of BaAka Pygmies $(n=950)$, south-west Central African Republic in 2015

\begin{tabular}{lcc}
\hline Co-invasions & $\begin{array}{c}\text { Number of } \\
\text { co-invasions }\end{array}$ & $\begin{array}{c}\text { Percentage of } \\
\text { all co-invasions }\end{array}$ \\
\hline A. lumbricoides + Hookworm & 456 & 67.8 \\
\hline A. lumbricoides + Trichuris trichiura & 154 & 22.9 \\
\hline A. lumbricoides + Giardia intestinalis & 106 & 15.8 \\
\hline
\end{tabular}

\section{DISCUSSION}

Gastrointestinal parasitic diseases usually reflect the economic status of a given population, its social and living conditions, access to healthcare facilities, and the level of health education. In developed countries, the rates of intestinal parasitic infections remain at a low level, and the most common infections are those caused by Enterobius vermicularis nematode (especially in the population of children) and Giardia intestinalis protozoa [12, 13]. In developing countries, especially those with a hot climate, the epidemiological situation is entirely different. In African countries, for example, parasitic infections are a serious public health issue. The situation is additionally worsened by the coexistence of many other infectious diseases, such as AIDS, tuberculosis and malaria [14, 15], and by the fact that a large number of food handlers are reported to have gastrointestinal infections. Screening tests conducted among street food handlers in Ethiopia showed that $45 \%$ of the study subjects were infected with at least one parasitic species; the infections with Ascaris lumbricoides were the most prevalent [16]; hookworm and Trichuris trichiura infections were also found to be widespread [17]. The presented findings are consistent with the results of previous studies according to occurrence of parasitic species.

Pygmy tribes inhabiting the rainforests of the Congo Basin are an example of a population exhibiting high rates of parasitic infections. Their unique semi-nomadic lifestyle, combined with the consumption of water and food from uncontrolled sources (which is not properly heat processed), increase the risk of infection with intestinal parasites, especially with nematodes and protozoa [9]. According to the findings of the, $90.5 \%$ of the tested group $(\mathrm{n}=950)$ were found to be infected with pathogenic parasites, of which the most common were infections caused by Ascaris lumbricoides (67.3\% of tested patients), hookworm (66.6\%), Trichuris trichiura (24.1\%) and Giardia intestinalis (18.4\%). Unfortunately, very little data is available on the prevalence of parasitic infections in the Central African Republic. Screening tests performed in the capital city of Bangui in the 1980's in a group of 3,352 residents revealed gastrointestinal parasitic infections in $46.8 \%$ of the subjects, with a clear domination of Ancylostoma duodenale (26.7\%); infections with more than one parasite species were found to be common [18]. A high rate of parasitic infections (88.2\%) with a domination of Ascaris lumbricoides (40.1\%) and Necator americanus (18.6\%), and large numbers of mixed infections (33.3\%), were revealed by screening tests conducted between 2015 - 2016 among 102 children living in rural areas in the southern parts of the Central African Republic [19]. The presented study which involved a group of BaAka Pygmies revealed polyparasitism in $70.8 \%$ of the study participants, with co-invasions of Ascaris lumbricoides and hookworm, Trichuris trichiura and Giardia intestinalis being the most common. It is very likely that the number of mixed parasitic infections would be even higher than the results suggest if more sensitive diagnostic methods were applied. Parasitological screening conducted in Mozambique seems to confirm this thesis; the number of co-invasions was found to be significantly higher when methods of molecular biology were used for testing [20].

Pygmy tribes, which are at a particularly high risk of exposure to a number of environmental and health risk factors, require special attention of the medical services. Because of the high prevalence of parasitic diseases in Central Africa, a large scale WHO-recommended deworming programme was initiated in the region [21]. The treatment of nematodes requires the use of albendazol $(400 \mathrm{mg})$ or mebendazol $(500 \mathrm{mg})$, while elimination of trematodes, especially Schistosoma flukes, requires the use of praziquantel $(40 \mathrm{mg} / \mathrm{kg})[22,23]$. Because the cost of deworming treatment is relatively low, it is an excellent method of preventing the spread of infections, especially from asymptomatic carriers. Although deworming programmes have clear advantages, they also have their limitations. The effects of such campaigns are often only temporary. In areas where parasitic infections are endemic, people have limited access to healthcare facilities and show poor personal hygiene habits, resulting in a significant proportion of patients quickly became reinfected. Therefore, the only effective method to eliminate intestinal parasitic infections in a community such as the Pygmy is not only the implementation of effective deworming programmes, but also to initiate ongoing health awareness campaigns. 


\section{CONCLUSIONS}

The prevalence of intestinal parasitic infections are high in the community of Pygmies inhabiting the south-western parts of the Central African Republic. Low economic status, limited access to uncontaminated drinking water and safe food, combined with poor sanitary conditions, contribute to the rapid spread of parasitic diseases in the Pygmy population. The negative test results obtained may prove the effectiveness of the periodic deworming programmes implemented by non-governmental organizations among local residents, and are voluntary with respect to informed consent principle.

\section{Aknowledgements}

The research project was accepted by the Bioethics Committee at the Military Institute of Medicine, Warsaw, Poland (Decision No. 4/WIM/2015, 21 Jan 2015) under the Declaration of Helsinki (1996) and in line with the European Union provisions on Good Clinical Practice for conducting clinical trials and testing medicinal products (1999) ratified by the Polish Bioethics Committee (March 1993). The authors are grateful to Father Wojciech Lula (a catholic mission superior and the manager of the healthcare center in Monasao, Central African Republic) and Ms. Elżbieta Wryk (a secular missionary of the catholic mission and the manager of the healthcare center in Bagandou, Central African Republic) for their excellent assistance and supervision in patient recruitment and collection of biological samples.

\section{REFERENCES}

1. Chacin-Bonilla L. Intestinal parasitic diseases as a global health problem. Invest Clin. 2013; 54(1): 1-4.

2. World Health Organization. Intestinal worms. Epidemiology, geographical distribution. Available at: https://www.who.int/intestinal_ worms/epidemiology/en/ (access: 2020.10.01).

3. Karagiannis-Volues DA, Biedermann P, Ekpo UF, Garba A, Langner E, Mathieu E, et al. Spatial and temporal distribution of soil-transmitted helminth infection in sub-Saharan Africa: a systemic review and geostatistical meta-analysis. Lancet Infect Dis. 2015; 15(1): 74-84.

4. Diggle PJ, Giorgi E. Geostatistical mapping of helminth infection rates. Lancet Infect. Dis. 2015; 15(1): 9-11.

5. Korzeniewski K, Lass A, Augustynowicz A, Konior M. The Prevalence of Intestinal Parasitic Infections Among Kosovar and Serbian Schoolchildren in Kosovo. Helminthologia. 2020; 57(3): 276-279.

6. El-Sherbini GT, Abosdera MM. Risk factors associated with intestinal parasitic infections among children. J Egypt Soc Parasitol. 2013; 43: 287-294.

7. Jourdan PM, Lamberton PH, Fenwick A, Addiss DG. Soil-transmitted helminth infections. Lancet. 2018; 391(10117): 252-265.

8. The United Nations Office for the Coordination of Humanitarian Affairs (OCHA). Central African Republic - situation report 23 Oct 2020.
Available at: https:/reliefweb.int/sites/reliefweb.int/files/resources/ Situation\%20Report\%20-\%20Central\%20African\%20Republic\%20 -\%2021\%20Oct\%202020_0.pdf (access: 2020.10.26).

9. Hewlett BS. (Ed.). Hunter-Gatherers of the Congo Basin; Cultures, Histories and Biology of African Pygmies. Transaction Publishers: New Brunswick and London 2014.

10. Garcia LS. Practical Guide to Diagnostic Parasitology. 2nd Ed. ASM Press: Washington DC, USA 2009.

11. Kettelhut M, Moody A, Edwards H, Chiodini PL. Evaluation of Parasep ${ }^{\infty}$ Faecal Parasite Concentrator. Hospital for Tropical Diseases, London, England. 2003.06.07. Available at: https://journals.plos.org/plosntds/ article/file?type $=$ supplementary\&id $=$ info: $\mathrm{doi} / 10.1371 /$ journal . pntd.0000386.s002 (access: 2020.10.01).

12. Friesen J, Bergman C, Neuber R, Fuhrmann J, Wenzel T, Durst A, et al. Detection of Enterobius vermicularis in greater Berlin, 2007-2017: seasonality and increased frequency of detection. Eur J Clin Microbiol Infect Dis. 2019; 38(4): 719-723.

13. Reh L, Muadica AS, Köster PC, Balasegaram S, Verlander NQ, Chercoles ER, et al. Substancial prevalence of enteroparasites Cryptosporidium spp., Giardia duodenalis and Blastocystis sp. in asymptomatic schoolchildren in Madrid, Spain, November 2017 to June 2018. Euro Surveill. 2019; 24(43): 1900241.

14. Mamo H. Intestinal Parasitic Infections among Prison Inmates and Tobacco Farm Workers in Shewa Robit, North Central Ethiopia. PLoS One. 2014; 9(6): e99559.

15. Vouking MZ, Enoka P, Tamo CV, Tandefok CN. Prevalence of intestinal parasites among HIV patients at the Yaound Central Hospital, Cameroon. Pan Afr Med J. 2014; 18: 136.

16. Tefera T, Mebrie G. Prevalence and Predictors of Intestinal Parasites among Food Handlers in Yebu Town, Southwest Ethiopia. PLoS One. 2014; 9(10): e110621.

17. Shiferaw MB, Mengistu AD. Helminthiasis: Hookworm Infection Remains a Public Health Problem in Dera District, South Gondar, Ethiopia. PLoS One. 2015; 10(12): e0144588.

18. Meunier DM, Georges MC, Georges AJ. Report on intestinal parasitosis in adults in an urban population of the Central African Republic. Bull Soc Pathol Exot Filiales. 1984; 77(3): 333-343.

19. Tekpa G, Fikouma V, Gbangba-Ngai E, Bogning Mejiozem BO, Ningatouloum Nazita, S, Koffi B. Epidemiological and clinical profile of intestinal parasitosis of children in rural areas in Central African Republic. Arch Pediatr. 2019; 26: 34-37.

20. Meurs L, Polderman AM, Vinkeles Melchers NV, Brienen EA, Verweij JJ, et al. Diagnosing Polyparasitism in a High-Prevalence Setting in Beira, Mozambique: Detection of Intestinal Parasites in Fecal Samples by Microscopy and Real-Time PCR. PLoS Negl Trop Dis. 2017; 11(1): e0005310.

21. Engels D. (Ed.). Preventive chemotherapy in human helminthiasis. Coordinated use of anthelminthic drugs in control interventions: a manual for health professionals and programme managers. Geneva: WHO/Department of Control of Neglected Tropical Diseases 2006. Available at: https://www.who.int/neglected_diseases/resources/ 9241547103/en/ (access: 2020.10.09).

22. Truscott JE, Turner HC, Farrell SH, Anderson RM. Soil-Transmitted Helminths: Mathematical Models of Transmission, the Impact of Mass Drug Administration and Transmission Elimination Criteria. Adv Parasitol. 2016; 94: 133-198.

23. Anderson RM, Turner HC, Farrell SH, Truscott JE. Studies of the Transmission Dynamics, Mathematical Model Development and the Control of Schistosome Parasites by Mass Drug Administration in Human Communities. Adv Parasitol. 2016; 94: 199-246. 